\title{
Creation of a collection of microorganisms - destructors of organic substances that are promising for bioremediation of technogenic disturbed lands in Kazakhstan Baigonusova Zh.A., Rysbek A.B., Kurmanbaev A.A.
}

RSE "National Center for Biotechnology" SC MES, Nur-Sultan, Republic of Kazakhstan E-mail: zhanatb71@mail.ru,kurmanbayev@biocenter.kz

Key message. The cultural-morphological and biochemical properties of 83 selected strains of organic substance destructor were studied. The analysis of nucleotide sequences of the genome of bacteria Bacillus cereus Fd 2 was performed. Keywords: surfactant destructor, oil destructor, fat destructor, production-valuable strain, identification

Collections of microbial cultures are fundamental to biotechnology. The cultures stored in the collections are the basis for using the achievements of Microbiology, genetics, and molecular biology in industry, agriculture, and medicine.

The purpose of the research was to create and replenish the collection of microorganisms with strains of organic substance destructor bacteria.

The generic identity of the isolated bacteria was determined on the basis of morphological, cultural and chemotaxonomic characteristics, using the "Determinant of Bergi bacteria" [1]. Tests for biochemical properties were used to differentiate microorganisms to the genus [2]. The identification of bacteria using MALDI-TOF mass spectrometry was performed by comparing data on the composition and ratio of peptides obtained by hydrolysis of proteins in the colony of the studied microorganism with similar data of typical strains from the database using the Biotyper 3.0 RTC program (Bruker Daltonics, Germany). Full-genome sequencing of Bacillus cereus FD 2 strains was performed on the Miseq, Illumina platform. Initially, bacterial DNA was isolated from the culture medium using a standard STAV method [3].

The objects of research were 83 active strains of oil and surfactant destructive bacteria isolated from the soils of Mangistau, Atyrau, Aktau regions, from the effluents of active silt of the treatment facilities of Nur-Sultan "Astana Su Arnasy", as well as from the wastewater of private baths and car washes.

Morphophysiological and biochemical properties of collection bacterial strains of fat destructors (Fd), surfactant destructors (Sd) and oil destructors (Od) were studied.

As a result of the analysis of 16 bacterial strains of fat destructors, 10 strains were gram-positive rods, 6 were gram-negative rods, all had oxidase and catalase activity. Microscopy of smears of surfactant destructor strains (Sd) revealed that 9 of them were gram-positive rods, 9-gram-negative rods, 1 strain was assigned to gram - positive cocci, and 1-to gram-negative cocci. Among the oil destructor bacteria (Od), 10 strains were gram-positive rods, 30 gram-negative rods, 2 strains were assigned to gram - positive cocci, and 5-to gram-negative cocci, 20 strains did not have oxidase activity, and 22 strains have catalase activity.

All the studied bacterial strains of organic destructors had catalase and oxidase activity, were capable of liquefying gelatin, carried out starch hydrolysis, did not form indole, and assimilated glucose, fructose, trehalas, sucrose, mannose, rhamnose and maltose, galactose and lactose.

54 bacterial cultures were identified to the genus and species using MALDI-TOF mass spectrometry.

In this study, the Fd - 2 active strain with lipase activity was selected from the collection of studied microorganisms for fullgenome sequencing.

Thus, a collection of active strains of bacteria - destructors of organic matter is obtained. All the studied strains of microorganisms can serve as the basis for creating preparations for cleaning the environment from xenobiotics.

This work was prepared as part of the BR05236334 project, funded by the Ministry of education and science of the Republic of Kazakhstan for 2018-2020.

1. Holt J. et al. The determinant of Bergi bacteria / TRANS. from English in 2 volumes / Moscow: Mir, 1997. - 800 p.

2. Tepper E. Z., Shilnikova V. K., Pereverzeva G. I. Practicum on Microbiology / ed. by V. K. Shilnikova. - Moscow: bustard, 2004. - $256 \mathrm{p}$.

3. Tamura K., Stecher G., Peterson D., Filipski A., and Kumar S. MEGA 6: Molecular Evolutionary Genetics Analysis Version 6.0 // Molecular Biology and Evolution. - 2013. - Vol.30. - P. 2725-2729 